\title{
REFLETINDO SOBRE A TRADUÇÃO DE CLARICE LISPECTOR PARA O ENSAIO LA FAIM DU TIGRE DE RENÉ BARJAVEL
}

\author{
REFLECTING ON CLARICE LISPECTOR'S TRANSLATION TO RENÉ \\ BARJAVEL'S BOOK LA FAIM DU TIGRE
}

\author{
Edilza Maria Medeiros Detmeringi \\ Arthur Antonio Santos Beserraii
}

RESUMO: Este trabalho apresenta uma reflexão sobre a tradução de Clarice Lispector para o ensaio La Faim du Tigre do francês René Barjavel (1966), com base em teorias e conceitos dos Estudos da Tradução, quais sejam: os processos de domesticação e de estrangeirização de Venuti (1995), os conceitos de Tradução, Adaptação e Transformação de Guidère (2008) e os enunciados da Teoria Funcionalista da Tradução de Nord (1991). O debate que se intenciona prospectar perpassa a análise das escolhas feitas pela tradutora e escritora brasileira, buscando identificar a maneira lispectoriana de traduzir. Percebe-se que se a escritora tenta manter o texto alvo o mais próximo possível do léxico e da estrutura da língua do texto fonte, em contrapartida omite trechos que causariam empecilhos à tradução. Este trabalho firma-se como reconhecimento da importância do legado de Lispector, só muito tardiamente descoberta e valorizada por suas traduções nos diversos idiomas com os quais atuou.

PALAVRAS-CHAVE: Estudos da Tradução. Visibilidade da tradução. Clarice Lispector.

ABSTRACT: This paper presents an analysis of Clarice Lispector's translation to René Barjavel's book La Faim du Tigre (1966) based on concepts and theories intrinsic to the Translation Studies domain: Venuti's processes of domestication and foreignization (1995), Guidère's concepts of Translation, Adaptation and Transformation (2008), and Nord's Functionalist Approach of Translation (1991). The debate presented here studies the choices made by the Brazilian translator in search of an identity: the purported Lispector's way of translating. One observes, among other things, that the translator adheres to the idea of maintaining the target text as close as possible to the structure and lexicon of the source language, while paradoxically omitting segments that could impose obstacles to the translation. This paper stands as a testament of the importance of Clarice Lispector's legacy as a translator - belatedly discovered and recognized - in the many languages which she worked with.

KEYWORDS: Translation Studies. Translator's Visibility. Clarice Lispector.

Submetido em: 15 out. 2018

Aprovado em: 29 nov. 2018

\footnotetext{
' Universidade Federal da Paraíba. E-mail: detmering@sti.ufpb.br.

ii Bacharelado em Tradução da Universidade Federal da Paraíba. E-mail: artutabr@hotmail.com. 


\section{Introdução}

Este artigo tem por objetivo apresentar uma tradução comentada do ensaio La faim du tigre do francês René Barjavel (1966) para o português brasileiro. O ensaio foi traduzido por Clarice Lispector em 1973 e publicado neste mesmo ano pela editora Artenova, a partir do texto originalmente escrito em língua francesa. As escolhas feitas pela tradutora e escritora brasileira são aqui discutidas, no intuito de identificar a maneira lispectoriana de traduzir e as marcas de visibilidade da tradutora. Assim, se apresenta uma racionalização sobre o processo tradutório do referido ensaio.

Devido à necessidade de trabalhos que apresentem objetivos semelhantes ao aqui definido, a presente proposta é justificada e imperativa, uma vez que apenas três artigos desenvolveram uma reflexão sobre o fazer tradutório de Clarice Lispector. Toda essa produção acadêmica é recente, se for levado em conta que Lispector começou a traduzir em 1941, antes mesmo de se iniciar como escritora. Ademais, suas atividades tradutórias foram encerradas em 1976, já bem próximo de sua morte, compondo um valoroso acervo que merece ser estudado e divulgado. Este trabalho posiciona-se como reconhecimento da importância do legado tradutológico de Lispector, cuja produção nos diversos idiomas com os quais atuou só muito tardiamente foi valorizada. O reconhecimento do valor dessas traduções se reflete na (ainda reduzida) produção acadêmica existente, que se configura como resultado de profunda e cuidadosa pesquisa e análise. Assim, os resultados trazem uma contribuição preciosa para a área denominada Estudos da Tradução.

Para citar a produção acadêmica existente, podem ser mencionados os trabalhos de André Luís Gomes (Entre espelhos e interferências: a problemática da tradução para Clarice Lispector - artigo submetido à revista Via Atlântica no ano de 2004); de Marcílio Queiroga ( $A$ voz da tradutora Clarice Lispector em livros infantojuvenis do gênero aventura - Tese de Doutoramento no ano de 2015); e de Rony Márcio Cardoso Ferreira (Clarice Lispector: uma tradutora em fios de seda - teoria, crítica e tradução literária - Tese de Doutoramento no ano de 2016). 
Lispector traduziu apenas do inglês, espanhol e francês para o português (dentre os mais variados gêneros textuais), apesar de ter sido fluente em seis idiomas. De forma mais detalhada, de um total de 40 textos traduzidos, 11 foram do francês, com destaque para o ensaio La faim du tigre, texto central deste estudo.

Destaca-se também o documentário médico-psicanalítico L’homme au magnétophone, do francês Jean-Jacques Abrahams (1970), cuja tradução foi publicada em 1978.

O presente estudo tenta trazer sua colaboração ao prospectar discussões que impulsionem futuras pesquisas, na intenção de difundir e valorizar o legado de Clarice Lispector. Assim, não esgota o tema, ratifica, porém, a importância de produções acadêmicas nesse sentido.

\section{Percurso metodológico}

A análise aqui ensejada acerca dos textos traduzidos é alicerçada em uma perspectiva teórica dos Estudos da Tradução. Para tanto, foi embasada nos processos de domesticação e de estrangeirização - conceitos aplicados por Lawrence Venuti (1995) -, com vistas a investigar a visibilidade da tradução e da tradutora; ainda, nos conceitos de Tradução, Adaptação e Transformação discutidos por Mathieu Guidère (2008), utilizados como recursos tradutórios; e também, nos enunciados da Teoria Funcionalista da Tradução, expostos por Christiane Nord (1991) - em especial, nas ideias de objetivo da tradução e de sua função na cultura de chegada.

Dessa forma, a trajetória metodológica deste estudo teve início com o exame de três trabalhos mencionados anteriormente, que discutem as traduções feitas por Clarice Lispector em língua inglesa. A partir desses trabalhos, procedeu-se à escolha, à busca e à leitura de textos escritos em francês e traduzidos por Clarice. Nesse sentido, a escolha do ensaio La faim du tigre se justifica por este pertencer a um gênero textual que permite escolhas tradutórias passíveis de serem problematizadas. Como passo seguinte, procedeu-se à busca e à leitura aprofundada da tradução do ensaio em pauta, realizada por Lispector. 
As intervenções identificadas nesse ensaio foram catalogadas para que se procedesse à análise das escolhas tradutórias com base nas teorias dos Estudos da Tradução mencionadas anteriormente. Procedeu-se então à classificação e à subclassificação de escolhas e estratégias utilizadas por Lispector em seu trabalho tradutório, quais sejam: acréscimos, omissões, domesticação, estrangeirização.

A subclassificação e sua justificativa será apresentada adiante. As próprias escolhas tradutórias de Lispector guiaram a escolha das categorias selecionadas para análise.

Por fim, foi feito um emparelhamento do texto fonte (em francês) com o texto alvo (em português) para identificar os trechos que apresentaram alterações ${ }^{1}$.

No tópico a seguir, serão apresentados exemplos das referidas intervenções da tradutora e percentuais de ocorrência das categorias identificadas.

\section{Discussão dos resultados}

Elencar alguns dos exemplos de alterações e prospectar uma breve discussão sobre as escolhas tradutórias de Lispector são a proposta deste tópico. A intenção ao iniciar a análise era tentar perceber se seria possível apreender o quanto da escritora Clarice Lispector estaria presente na tradutora, quão transgressora ela se manteria na tradução, e ainda quais seriam as marcas da tradutora. Verificar-se-á a seguir se essas intenções se confirmaram. Foram escolhidos dois exemplos de omissão e um de 'estrangeirização' para ilustrar o que foi extraído da análise do ensaio.

Os exemplos 1.a. e 1.b. a seguir ilustram uma omissão que permite refletir acerca de projeto tradutório (enfatizado por NORD, 1991). Apesar da importância dada por teóricos dos Estudos da Tradução a esta etapa do processo tradutório

\footnotetext{
${ }^{1}$ Por uma questão de espaço e por não ser o objetivo do presente trabalho, não será aqui apresentado o emparelhamento de todos os trechos do ensaio. A análise recairá sobre exemplos pontuais extraídos da catalogação das alterações identificadas.
} 
(o projeto), parece não ter sido elaborado nenhum projeto de tradução para o presente ensaio. Observe-se.

Ex. 1.a. II n'y a pas de mot dans la langue française pour désigner cette infime quantité de matière, ce moins que fétu, ce soupçon.

1.b. Não há palavra, em qualquer língua, para designar esta íntima quantidade de matéria, menor que feto, apenas um fragmento.

No exemplo 1.b., ocorre um apagamento cultural, ou seja, enquanto o autor destaca um traço, uma limitação da língua francesa, a tradutora omite tal estratégia e acaba por estender esse traço a todas as línguas existentes, universalizando-o, generalizando-o.

A interpretação textual resultante da tradução altera a mensagem do texto fonte e o consequente entendimento desta. Um projeto tradutório com propósitos especificados e que levasse em conta o provável receptor do texto alvo poderia esclarecer os motivos desse apagamento.

O segundo caso de omissão que vale destacar não se limita a um trecho apenas, mas a um parágrafo inteiro. Também neste caso, a existência de um projeto de tradução auxiliaria na compreensão dos motivos que levaram a tradutora a suprimir o trecho em destaque.

Ex. 2.a. Dans des écoles sévères, nous élevons des spécialistes qui sont chargés de faire l'inventaire total de l'usine. Chacun dans son domaine, ils comptent les volants, les pistons, les pignons, les boulons, les presses, les tours, les axes, les cylindres, les soupapes, les turbines, mesurent le pas de vis de l'écrou qui tient le manche de la balayette, pistent la câblerie, notent des relations constantes de cause à effet dont ils tirent les lois de fonctionnement de la machinerie : si on freine le rotor il va moins vite, ce qui passe au marteau-pilon est aplati, etc. Ils donnent un nom à chaque vis, notent ses dimensions et son poids sur une fiche, son emplacement sur un plan, ses ressemblances ou ses différences avec d'autres vis sur un arbre évolutionniste, analysent son métal, scrutent ses molécules, 
fabriquent de monstrueuses machines pour essayer de produire des molécules semblables et peut-être, avec énormément d'intelligence, d'efforts, de chance, et des moyens matériels considérables, une vis tout entière... D'où vient l'énergie qui fait fonctionner l'usine ? Ils ne peuvent pas nous le dire et peu nous importe, puisqu'ils nous ont appris comment l'utiliser pour nos petits besoin. Que produit l'usine ? Ce n'est pas notre souci.

2.b. Em escolas severas escalamos especialistas que são encarregados de fazer o inventário total da usina. Que produz a usina? Essa não é preocupação nossa.

Nesse exemplo 2.b., apresentado como a tradução do exemplo 2. a. percebe-se (trecho em itálico) que todo o argumento e a sua justificativa postos pelo autor foram omitidos, alterando a compreensão textual, privando o leitor final de informações que ampliariam o seu entendimento sobre o texto. Omissão semelhante não foi percebida em outras partes do texto traduzido por Lispector. Tendo-se em mente as teorizações de Guidère (2010), observa-se que a tradutora parece ter efetuado uma adaptação textual (uma transformação, por que não dizer) no momento em que suprimiu uma quantidade significativa de texto.

Em mais uma alteração, exemplo 3. b., a Lispector acresce um neologismo ao seu texto: "se entremassacram". A tradução esperada para o sintagma "elles s'entre-massacrent" seria "massacram uma a outra", ou ainda, "se massacram", mas a tradutora utilizou um verbo que não faz parte do português brasileiro, efetuando uma tradução 'ao pé da letra'. Essa estratégia sugere influência do texto de partida sobre o seu fazer tradutório e apresenta uma estrangeirização - utilizando aqui o termo de Venuti (1995).

Ex.3.a. Elles s'entre-massacrent inexorablement, et si ingénieusement que la mort nourrit la vie et permet à la partie de se poursuivre et de progresser. 
3.b. Elas se entremassacram inexoravelmente, e com tal engenho, que a morte alimenta a vida e permite que a partida prossiga e progrida.

O verbo entremassacrar-se não existe no português brasileiro e, por isso, a escolha recai no processo de estrangeirização problematizado por Venuti. Isso sugere que a tradutora ficou presa ao texto fonte e reproduziu o vocábulo que faz parte do léxico da língua de partida.

Por fim, vale destacar que os exemplos discutidos neste tópico representam apenas 3,9\% dos casos de alteração textual efetuada por Clarice Lispector na tradução do ensaio em pauta. A amostragem está limitada ao escopo deste artigo. A seguir, é apresentado um panorama das alterações em paralelo com seus percentuais, que permite uma visão mais geral do que foi encontrado.

Quadro 1: Categorias encontradas no texto alvo e seus respectivos percentuais

\begin{tabular}{|l|c|}
\hline Categorias (total 104 ocorrências) & Valor percentual \\
\hline Omissão de marcas do autor & $55,8 \%$ \\
\hline $\begin{array}{l}\text { Escolha pela estrangeirização (apego ao texto } \\
\text { fonte) }\end{array}$ & $30,8 \%$ \\
\hline Omissão de elementos da cultura francesa & $12,5 \%$ \\
\hline Parágrafo inteiro (mais de 10 linhas) & $0,9 \%$ \\
\hline
\end{tabular}

Fonte: Dados da pesquisa.

Foram identificadas 104 ocorrências em todo o texto traduzido - 58 omissões de marcas do autor (55,8 \%), 32 escolhas pela estrangeirização $(30,8$ $\%$, denotando apego ao texto fonte), 13 omissões de elementos da cultura francesa (12,5\%) e 1 omissão de um trecho com mais de 10 linhas $(0,9 \%)$.

Diferentemente dos resultados do trabalho de Queiroga (2014), não foi encontrado nenhum caso de acréscimo (que este autor denomina de "amplificação" - maior ocorrência encontrada em sua pesquisa) no texto alvo, o que se esperava encontrar neste ensaio La faim du tigre. Na presente análise, também foram encontradas algumas tentativas de domesticação, ou seja, algumas tentativas de aproximação do texto final à cultura de chegada foram 
realizadas pela tradutora, postura raramente identificada por Gomes (2004) em sua pesquisa. Ferreira (2016) faz em seu trabalho uma menção a projetos tradutórios realizados por Lispector, que a mesma divulga em uma crônica. Nela, a escritora e tradutora se detém em comentários sobre suas estratégias enquanto tradutora, de uma forma mais geral. No entanto, não se identificou um projeto tradutório para o ensaio aqui discutido.

Verifica-se que as omissões encontradas no ensaio La faim du tigre alteram o entendimento e o impacto do texto alvo, distanciando-o do texto fonte. O apagamento de registros da cultura de partida não permite que o leitor do texto alvo compartilhe das ideias do autor do texto fonte e privam-no de conhecer aspectos que permeiam a cultura do texto de partida. Como já mencionado, não foi apresentado um projeto de tradução nem foi adicionada uma nota de tradução ao texto produzido por Lispector e publicado pela Artenova, que justificassem as escolhas tradutórias verificadas no ensaio em análise.

\section{Considerações finais}

Este artigo que objetivou apresentar uma reflexão sobre a tradução de Clarice Lispector para o ensaio La faim du tigre do francês René Barjavel permitiu conhecer um pouco mais sobre a tradutora sem que se possa definir a maneira lispectoriana de traduzir. Assim, chega-se ao final desta reflexão entendendo que a análise foi apenas iniciada, sendo necessário uma ampliação do corpus analisado para que se chegue a conclusões mais categóricas sobre a maneira lispectoriana de traduzir.

Neste ensaio, contudo, a tradutora doméstica (com apagamento ou omissão do teor cultural), ao mesmo tempo em que estrangeiriza (ao criar neologismo -> verbo 'entremassacrar'). Percebe-se, assim, que a escritora tenta manter o texto alvo o mais próximo possível do léxico e da estrutura da língua do texto fonte, e que realiza, entretanto, omissões em passagens do texto que podem causar empecilhos à tradução.

Aqui não está sendo emitido juízo de valor, pois compreende-se o aspecto provisório de uma tradução. Além do mais, acreditando-se que a própria Clarice Lispector traduziu o texto em análise, não se pode aferir que se encontrou sua 
maneira de traduzir, uma vez que não foi identificado um padrão, nem foi analisada a totalidade das obras que ela traduziu do francês, do inglês e do espanhol. Leve-se em conta, ainda, que os resultados desta análise apresentam discrepâncias em relação àquelas divulgadas pelos três autores mencionados no tópico anterior (GOMES, 2004; FERREIRA, 2016; QUEIROGA, 2014).

Pode-se, no entanto, inferir que as alterações efetuadas são em si um ato transgressor, cujos motivos permanecem desconhecidos, uma vez que não foi apresentado um projeto de tradução específico para o ensaio em pauta. Também não foi possível verificar o quanto da escritora esteve presente na tradutora Clarice Lispector, pela ausência dessas justificativas para suas interferências no texto, ou seja, pela ausência de materiais explicativos, como por exemplo, paratextos, que registrassem o processo tradutório.

Aponta-se como sugestão para futuros trabalhos a pesquisa em todas as obras francesas traduzidas por Lispector acerca das alterações encontradas no ensaio em análise. Vislumbra-se também a possibilidade de uma buscar por padrões tradutórios relacionados a cada um dos gêneros textuais traduzidos.

Importante ressaltar que a contribuição deste trabalho se constitui em reconhecer a importância das traduções feitas por Clarice Lispector, sobremaneira com a língua francesa, e estimular a realização de novas e mais aprofundadas pesquisas, objetivando a ampliação da discreta produção acadêmica sobre o trabalho desta tradutora.

\section{Referências}

ABRAHAMS, J. J. L’homme au magnétophone. Paris: Le Sagittaire, 1976.

BARJAVEL, R. La faim du tigre. Paris: Denoël, 1966.

BARJAVEL, R. A fome do tigre. Tradução: Clarice Lispector. Rio de Janeiro: Artenova, 1973.

FERREIRA, R. M. C. Clarice Lispector: uma tradutora em fios de seda (teoria, crítica e tradução literária). 2016. 365 f. Tese (Doutorado em Literatura) - Instituto de Letras, Universidade de Brasília, Brasília, 2016.

GOMES, A. L. Entre espelhos e interferências: a problemática da tradução para Clarice Lispector. São Paulo: Via Atlântica, 2004. 
GUIDÈRE, M. Introduction à la traductologie. Bruxelles: Groupe de Boeck, 2010.

NORD, C. Text analysis in translation: theory, methodology and didactic application of a model of translation-oriented text analysis. Amsterdam; Atlanta: Rodopi, 1991.

QUEIROGA, M. G. de. A voz da tradutora Clarice Lispector em livros infantojuvenis do gênero aventura. 2014. 224 f. Tese (Doutorado em Estudos da Tradução) - Centro de Comunicação e Expressão, Universidade Federal de Santa Catarina, Florianópolis, 2014.

VENUTI, L. The translator's invisibility: a history of translation. London and New York: Routledge, 1995. (Translation Studies Collection).

VENUTI, L. Translation community. In: VENUTI, L. The translation studies reader. New York: Utopia, 2000. 